\title{
CHILD-ORAL IMPACTS ON DAILY PERFORMANCES INDEX IN INDONESIA: CROSS-CULTURAL ADAPTATION AND INITIAL VALIDATION
}

\author{
Avina Anin Nasia ${ }^{1 *}$, Wulandari Arumrahayu ${ }^{2}$, Robbykha Rosalien ${ }^{2}$, Diah Ayu Maharani ${ }^{3}$ and Melissa \\ Adiatman ${ }^{3}$ \\ ${ }^{1}$ Department of Dentistry, Faculty of Medicine, Diponegoro University, Semarang, 50275, Indonesia, ${ }^{2}$ Oral \\ Epidemiology and Clinical Studies in Dentistry Research Cluster, Faculty of Dentistry, University of Indonesia, \\ Jakarta, 10430, Indonesia, 'Department of Preventive and Public Health Dentistry, Faculty of Dentistry, University of \\ Indonesia, Jakarta, 10430, Indonesia.
}

*Corresponding author: Avina Anin Nasia

Email: avina.anin@fk.undip.ac.id

\begin{abstract}
The study was conducted to develop and provide initial validation results for an Indonesian version of the Child-Oral Impacts on Daily Performances measure among children aged 12-15 years in Jakarta. The Child-OIDP followed an established process of cross cultural adaptation. The face and content validity, internal consistency reliability, and discriminant validity of the Indonesian version of the Child-OIDP were assessed by evaluating its psychometric properties. This was accomplished through a cross-sectional study of 502 participants using a random sampling method to select 6 of 287 schools among all public junior high schools in Jakarta. Clinical assesment was done according to the Indonesian version of the Child-OIDP. Result of this study confirmed that the cross-cultural adaptation process of the Indonesian Child-OIDP was well established. All the inter-item correlation coefficients among the eight items of ChildOIDP ranged from 0.12 to 0.41 . The corrected item-total correlation coefficients ranged from 0.37 to 0.51 . The Cronbach's alpha coefficient was 0.74. The measure was able to discriminate between different clinical groups in terms of pulpal involvement, ulceration, fistula, and abscess (PUFA), gingival index (GI), and plaque index (PI). Overall, 64.9\% of the participants reported at least one oral impact in the past 3 months. The Indonesian version of the Child-OIDP demonstrated excellent internal consistency reliability and was well able to discriminate between different clinical groups among children aged 12-15 years in Jakarta.
\end{abstract}

Keywords: Children, oral health, quality of life, validity

\section{INTRODUCTION}

Traditional methods used to assess dental health are not able to exhibit a true picture of how dental health problems influence the quality of life $^{1}$. In fact, the need for oral health has been predominantly estimated using professionally based measures, which are also known as normative needs ${ }^{2}$. Studies in this field have developed the concept of "oral health-related quality of life" 3,4 , which breaks down into the following four aspects: functional factors, psychological factors, social factors and the existence of discomfort or pain ${ }^{1}$. Thus, OHRQoL instruments play a significant role alongside clinical measurement for estimating oral health needs and status of individuals ${ }^{1,4-8}$. Various instruments have been developed to measure OHRQoL, such as the Oral Impact on Daily Performance ${ }^{9}$, Oral Health Impact Profile ${ }^{10}$, and the Geriatric Oral Health Assessment Index ${ }^{11}$.

Some authors have adapted these instruments to apply them on children and adolescents. One of the measurements developed specifically for children is the Child-Oral Impact on Daily Performance $^{12}$. To be applicable to different populations, these measures must undergo meticulous cross-cultural adaptation processes and appropriate testing for key psychometric properties. In Indonesia, no such validated instruments are currently available that could be applied in a children setting, which indicates a gap for the development of this research field in this community.

Therefore, the aim of this study was to develop and provide initial validation results for an Indonesian version of the Child-OIDP measure among children aged 12-15 years in Jakarta. The findings of the study may provide valuable insights into the role of developing a better QoL particularly among children living in Indonesia.

\section{METHODOLOGY}

This cross-sectional study was performed in children aged 12-15 years in Jakarta, Indonesia. The study subjects were selected using a random sampling method from all public junior high schools in Jakarta which was done using software from the official website of the Education Office of Jakarta. The schools were enlisted from six out of 287 schools in Jakarta. All children aged 12-15 years in the school were included in this study. The study was approved by the Ethics Committee of the Faculty of Dentistry, University of Indonesia. Data were collected through a selfadministered questionnaire, followed by a clinical dental examination. In this study, the Child-OIDP questionnaire was used to measure the OHRQoL of 
children. The Child-OIDP index has a scoring system that measures the oral impacts by using frequency and severity scores; multiplying them gives each performance scores and adding the performance scores results in a sum impact score. Then the sum was divided by the maximum possible score and multiplied by 100 to give a percentage score. The scoring system enables public health practitioner to prioritise health care based on the level of impact scores of children; those with higher impact scores on their quality of life should get treatment earlier than those with lesser impact scores ${ }^{12}$.

\section{Cross-cultural Adaptation and Validation Methodology}

In this study, the Child-OIDP questionnaire was used to measure the oral health-related quality of life of children ${ }^{12}$. The Child-OIDP assesses impacts of oral health problems on some daily performances: eating, speaking, cleaning teeth, smiling, emotional stability, relaxing, doing schoolwork and social contact ${ }^{12}$. In this study, participants were asked solely about the presence of each oral impact. They were asked whether the child had experienced these impacts in the past 3 months. However, we did not follow it up with the Child-OIDP questions on frequency and severity thus it would be discussed as one of the limitation of this study.

The Child-OIDP has been developed in the English language. To be applied appropriately in Indonesia, it had to undergo cross-cultural adaptation and linguistic validation for the Indonesian language. However, this study will solely cover the cross-cultural adaptation, analyse its internal consistency reliability, and initial validation of the Indonesian Child-OIDP. The comprehensive validation is part of the future plans but it will not be held in this study.

These processes were accomplished through the following steps:

Stage 1: Review and conceptual definition

The whole process began with clarifying the concepts covered by each item of the original Child-OIDP in order to ensure that they were reflected appropriately in the target language. This review process was undertaken by Avina Anin Nasia (Student, MSc Dental Public Health UCL 2015-2016), Diah Ayu Maharani (Lecturer in the Faculty of Dentistry, University of Indonesia). This required a comprehensive review of the ChildOIDP by the research team in the target country, including the interpretation of each item and identification of potential problematic items or issues. It was followed by discussions between the research team in the target country and the team at University College London.
Stage 2: Forward translation and primary pilot testing

The Child-OIDP was then forward translated independently by Nasia and Robbykha Rosalien (Research Assistant at the Faculty of Dentistry, University of Indonesia). The forward translation and primary pilot testing phase followed particular steps:

1. Each translator produced the forward translation of the original instrument into the Indonesian language independently without having any discussion with the other translator or the research team.

2. After the production of two translations of the Child-OIDP into Indonesian, a consensus version was established by reconciling the differences between the translated versions. This was achieved through a discussion via Skype between the two translators, with the objective of observing cultural sensitivity and ensuring appropriate wording.

3. This consensus version was further pilot-tested on a small sample of 10 children aged 12-15. At this stage, the research team in the target country was in contact with the UCL team and enquired if there was any change needed.

4. The research team in Indonesia wrote a report explaining the translation problems (for example, difficulties with understanding the original English Child-OIDP, difficulties with translation into the Indonesian language in relation to the Child-OIDP items) and the solutions developed and applied.

5. At this phase, the research team in the target country was in contact with the UCL team and enquired if changes were needed.

Stage 3: Backward translation, review and development of the Indonesian version

The consensus version was then backward translated into English by Phillip Henry (a British expatriate who lives in Indonesia), who had no prior knowledge of the original English text of the Child-OIDP. The backward translated version was then carefully reviewed by the research team in the target country and UCL, in order to determine whether it appropriately reflected the original Child-OIDP and to find any possible problematic items or discrepancies with the original ChildOIDP.

A final decision about the appropriateness of the translation was then made by UCL, which resulted in an agreed-upon (by UCL and the research team in Indonesia) version of the Child-OIDP in Indonesia.

Stage 4. Pilot testing (cognitive debriefing) and approval of the target version

This stage aimed to assess the clarity, appropriateness and cultural relevance of the target language version of the instrument. It involved the application of the instrument to 10 
Indonesian children aged $12-15$ years and living in Indonesia. This was conducted by Nasia and Rosalien. This pilot testing included conducting individual in-depth, face-to-face structured interviews. These interviews began with the administration of the Indonesian Child-OIDP and were followed by a detailed discussion about the understanding and the difficulty of comprehending each item of the Child-OIDP by the participating children. Since there were not any cases of difficulty, alternative suggestions were not needed.

The testing was conducted on children of the same age in a different area in Jakarta. Undoubtedly, this process had some common features with the face and content validity and it contributed considerably to this purpose. However, it is better to appropriately assess the content and face validity after the final target language version has been agreed. After the completion of this stage, Nasia and Rosalien had a discussion about the result. Rosalien made a note after the interviews were conducted.

\section{Stage 5: Psychometric testing of the target version}

Finally, after the cross-cultural adaptation process had been completed, the Indonesian version of the Child-OIDP was subject to initial psychometric validation. At a first stage, this should necessarily involve the assessment of reliability and validity. While face and content validity is assessed through discussions and pilot studies, the assessment of internal reliability, construct and criterion validity requires a larger sample size (usually around 100 people) in a crosssectional design ${ }^{13}$.

Face and content validity refers to the concepts that form the minimum requirement for validation. Face validity shows whether the instrument gauges the desired qualities, while content validity reveals whether the instrument samples all the relevant or important domains, and refers to the extent to which the items are sensible and show the intended domain of interest. Face and content validity can be examined through a small-scale pilot study of a sample drawn from the target population ${ }^{13}$.

All the procedures explained above aim to explore the comprehensiveness of the Child-OIDP items and the relevance and understanding of the content of the questionnaire. Despite their empirical nature, the importance of these procedures is unquestionable, as they represent a measure of the acceptance of the instrument by those who will ultimately use it ${ }^{14}$.

Reliability assessment refers to internal reliability, as well as to test-retest reliability. The concept of internal consistency or homogeneity explains the different items of the Child-OIDP that should measure different aspects of the same characteristic. The internal consistency assessment needs a cross-sectional study of a sample from the target population and taking into account the following statistics calculation ${ }^{13}$ :

1. Inter-item correlation coefficient for the different Child-OIDP items

It describes the correlation of each item with the sum of all remaining items ${ }^{13}$.

2. Corrected item-total correlations for the different Child-OIDP items

It refers to the correlation of the item designated with the summated score for all other items ${ }^{13}$.

3. Cronbach's Alpha (a) coefficient

Cronbach's alpha coefficient is a method of assessing internal consistency and is most frequently used for this purpose. It is a function of both the average inter-item correlation and the number of items in a scale, and it increases as either of these increases. Coefficient above 0.7 is mostly regarded as reliable for psychometric scales. However, it is advisable that values should be above $0.8^{15}$ or even 0.9 (perfectly reliable) ${ }^{16}$ Additionally, one of the most useful applications of Cronbach's alpha coefficient lies in the scale development and the item selection. If Cronbach's alpha changes little when an item is deleted, then that item becomes a candidate for removal from the scale ${ }^{13}$.

4. Alpha if item deleted

It represents the scale's Cronbach's alpha reliability coefficient for internal consistency if an individual item is removed from the scale ${ }^{13}$.

Moving on to the assessment of validity, this should cover the face and content validity, but should also extend to construct and criterion validity. Those type of validity has been discussed on the chapter of literature review. To reinforce, as there is no gold-standard for OHRQoL measurement, criterion validity may not be possibly done thus in such a case the construct validity becomes more important.

Owing to the limited time of this study, data were gathered merely to assess the presence of the impact of the oral health status on daily performances. In this study, we gauged the prevalence of oral impacts on daily performances among children aged 12-15 using the Child-OIDP without evaluating the frequency and severity of each oral impact. Furthermore, we gathered clinical data through DMFT, periodontal status and some additional information: the gender and the education level of the parents.

\section{Measurement of Variables}

Due to the limited time of this study, data were collected only to assess the presence of the impact of the oral health status on daily performances. In this study, we gauged the prevalence of oral impacts on daily performances among children aged 12-15 years using the ChildOIDP without evaluating the frequency and 
severity of each oral impact. Furthermore, clinical data were collected through DMFT, periodontal status and some additional information: such as the gender and the education level of the parents. The clinical assessment was conducted by one examiner. Ten percent from total respondent were examined twice in order to conduct reliability assessment.

\section{Data Analysis}

Psychometric analysis of the Indonesian ChildOIDP index involved the assessment of internal reliability, as well as face and content validity and initial discriminant validity. Face and content validity was gauged through the translation and linguistic validation process, through discussions between the research team in Indonesia and the UCL team. Furthermore, pilot testing was conducted among children aged 12-15 years, from a similar background, before the primary study. All clinical data were coded into binary variables reflecting the prevalence of their clinical problems. The internal reliability of the ChildOIDP was measured using Cronbach's alpha coefficient, inter-item correlations and corrected item-total correlations. Cronbach's alpha if item deleted, and inter-item and item-total correlation coefficients were calculated using Pearson correlation coefficients (PCC). Comparison of the prevalence of oral impact based on age and gender was done using chi-squared test. Comparison of the prevalence of impact with the presence of oral health problem indicators was also done using chi-squared test. Correlation between the prevalence of impact and the presence of oral health problems indicator was determined using logistic regression analysis adjusted by age, gender, and education status of parents.

Data were subsequently analysed using the STATA statistical package. The cut-off level for statistical significance was set at 0.05 .

\section{RESULTS}

Table 1 shows the characteristics of the 502 children included in this study. The majority of the participants were girls (54\%), 14 years old $(35.7 \%)$, and around two-thirds finishing secondary education.

Table 1. Socio-demographic characteristics of the study participants $(n=502)$

\section{Socio-demographic Characteristics}

\begin{tabular}{|c|c|c|}
\hline \multicolumn{3}{|l|}{ Gender } \\
\hline Boys & 231 & $46 \%$ \\
\hline Girls & 271 & $54 \%$ \\
\hline \multicolumn{3}{|l|}{ Age (years) } \\
\hline 12 & 114 & $22.7 \%$ \\
\hline 13 & 169 & $33.7 \%$ \\
\hline 14 & 179 & $35.7 \%$ \\
\hline 15 & 40 & $8.0 \%$ \\
\hline \multicolumn{3}{|l|}{ Father's education } \\
\hline Primary ( $\leq 6$ years) & 52 & 10.4 \\
\hline Secondary (>6 $\leq 12$ years) & 361 & 71.9 \\
\hline Tertiary (>12 years) & 89 & 17.7 \\
\hline \multicolumn{3}{|l|}{ Mother's education } \\
\hline Primary ( $\leq 6$ years) & 92 & 18.3 \\
\hline Secondary (>6 $\leq 12$ years) & 343 & 68.3 \\
\hline Tertiary (>12 years) & 67 & 13.3 \\
\hline $\begin{array}{l}\text { Cross-cultural Adaptation } \\
\text { Review and conceptual definition } \\
\text { All items of relevant content in the English version } \\
\text { of Child-OIDP can be adequately reflected in the } \\
\text { Indonesian version. }\end{array}$ & \multicolumn{2}{|c|}{$\begin{array}{l}\text { Forward translation and primary pilot testing } \\
\text { The research team in Indonesia conducted pilot } \\
\text { testing using the translated versions of the } \\
\text { questionnaire through interviews among } 10 \\
\text { children aged } 12-15 \text { years. All of them understood }\end{array}$} \\
\hline
\end{tabular}

3

(\%)
Forward translation and primary pilot testing The research team in Indonesia conducted pilot testing using the translated versions of the questionnaire through interviews among 10 children aged $12-15$ years. All of them understood 
the items in the Child-OIDP.

Backward translation, review and development of the Indonesian version

There was one difference between the original version and the backward translated version. In addition, it was found that one item was lost during the translation stage. The item "loose milk teeth" was backward translated into "lose milk teeth," rather than "moving teeth." This was subsequently corrected at this stage through the discussion between the research team in Indonesia and the UCL.

Pilot testing (cognitive debriefing) and approval of the target version.
All participants clearly understood the entire questionnaire and the content of the individual questions. This led to the conclusion that this latest consensus version was appropriate and culturally relevant for children in Indonesia.

Internal consistency reliability

Overall, $64.9 \%$ of the participants reported having at least one oral impact affecting their daily performance in the past 3 months (Table 2). The most prevalent impact was cleaning teeth $(40 \%$ of children), followed by impacts on difficulty eating (33.5\%) and emotional stability (29.9\%).

Table 2. Prevalence of oral impacts according to age and gender $(n=502)$

\begin{tabular}{|c|c|c|c|c|c|c|c|}
\hline \multirow{3}{*}{ Child-OIDP items } & \multirow{3}{*}{$\%(n)$} & \multirow{2}{*}{\multicolumn{2}{|c|}{$\begin{array}{c}\text { Age } \\
\%\end{array}$}} & \multirow{3}{*}{$\mathrm{p}$-value } & \multirow{2}{*}{\multicolumn{2}{|c|}{$\begin{array}{c}\text { Gender } \\
(\%)\end{array}$}} & \multirow{3}{*}{$\mathrm{p}$-value } \\
\hline & & & & & & & \\
\hline & & $\begin{array}{l}12-13 \\
y .0 .\end{array}$ & $\begin{array}{l}14-15 \\
\text { y.o. }\end{array}$ & & Boys & Girls & \\
\hline Eating & $33.5(168)$ & 37 & 29 & 0.051 & 33 & 33 & 0.954 \\
\hline Speaking & $15.9(80)$ & 16 & 16 & 0.787 & 19 & 13 & 0.079 \\
\hline Cleaning teeth & $40.0(201)$ & 37 & 43 & 0.179 & 41 & 39 & 0.521 \\
\hline Sleeping/relaxing & $19.0(95)$ & 22 & 16 & 0.115 & 19 & 19 & 0.789 \\
\hline Emotional stability & $29.9(150)$ & 27 & 34 & 0.092 & 29 & 30 & 0.841 \\
\hline $\begin{array}{l}\text { Smiling/showing } \\
\text { teeth }\end{array}$ & $19.1(96)$ & 19 & 18 & 0.667 & 21 & 18 & 0.384 \\
\hline $\begin{array}{l}\text { Doing school } \\
\text { activity }\end{array}$ & $9.6(48)$ & 8 & 10 & 0.528 & 13 & 6 & 0.016 \\
\hline Social interaction & $11.4(57)$ & 9 & 13 & 0.241 & 16 & 7 & 0.002 \\
\hline $\begin{array}{l}\text { At least one oral } \\
\text { impact }\end{array}$ & $64.9(326)$ & 65 & 65 & 0.967 & 66 & 64 & 0.709 \\
\hline
\end{tabular}

${ }^{*}$ chi-squared test

Overall, the prevalence of oral impacts was not different between the two age groups (Table 2). In both gender group, the prevalence of oral impacts was primarily not statistically different between the two groups, except in the presence of oral impacts on doing school activity and social interaction that was higher among boys than among girls. 
Table 3. Reliability analysis: Inter-item correlation coefficient matrix for the Indonesian-version of the Child OIDP

\begin{tabular}{lccccccc}
\hline & Eating & Speaking & $\begin{array}{l}\text { Cleaning Sleeping/ } \\
\text { teeth }\end{array}$ & $\begin{array}{l}\text { Emosional } \\
\text { Relaxing }\end{array}$ & Smiling & $\begin{array}{l}\text { School Social } \\
\text { Acitivity }\end{array}$ \\
\hline Interaction
\end{tabular}

Table 4. Reliability analysis: Corrected item-total correlations

\begin{tabular}{lcc}
\hline & $\begin{array}{c}\text { Corrected item-total } \\
\text { correlation }\end{array}$ & $\begin{array}{c}\text { Cronbach's alpha if item } \\
\text { deleted }\end{array}$ \\
\hline Eating & 0.48 & 0.69 \\
Speaking & 0.37 & 0.72 \\
Cleaning teeth & 0.45 & 0.70 \\
Sleeping/relaxing & 0.51 & 0.69 \\
Emotional stability & 0.49 & 0.69 \\
Showing teeth & 0.37 & 0.72 \\
Doing school activities & 0.37 & 0.72 \\
Social interaction & 0.40 & 0.71 \\
\hline
\end{tabular}

Cronbach's alpha $=0.74$

In terms of internal reliability consistency, all the inter-item correlation coefficients among the eight items of Child-OIDP were positive (Table 3). The corrected item-total correlation coefficients ranged from 0.37 (speaking, smiling, and doing school activities) to 0.51 , (relaxing//sleeping). The Cronbach's alpha coefficient was 0.74 (Table $4)$.

Discriminant Validity of the Indonesian ChildOIDP regarding Different Clinical Groups

The mean number of decayed, missing, and filled teeth (DMFT) was $4.40 \pm$ 3.07. DMF was predominantly determined by decayed teeth $(87.3 \%)$.

As shown in table 5 , there were significant differences in the prevalence of oral impacts for all the other three clinical measures. More specifically, children having at least one condition indicated by PUFA index showed much higher prevalence of oral impacts $(74.8 \%)$ than those who did not have conditions (62.3\%) $(p=0.016)$. In particular, children who had moderate or severe deposits of plaque reported much higher prevalence of oral impacts $(72.0 \%)$ than those who had normal or small deposits of plaque $(61.4 \%)(p=0.018)$.

The associations were significant $(p<0.05)$ with the exception of current decay $(p>0.05)$. After adjusting for the confounders age, gender, and parental education status, children having at least one conditions indicated by PUFA, and moderate or severe deposits of plaque, and those with moderate or severe gingivitis were 1.79 (1.112.90), 1.62 (1.08-2.42), 1.94 (1.25-3.00) times more likely to report an oral impact than children who did not have conditions indicated by PUFA index, and had normal or small deposits of plaque, and those with normal or mild gingivitis, respectively. 
Table 5. Associations between prevalence of oral impacts and clinical oral health measures: unadjusted and adjusted for age, gender, and parental education status $(n=502)$

\begin{tabular}{|c|c|c|c|c|c|c|c|}
\hline & \multicolumn{3}{|c|}{ Prevalence of Oral Impacts* } & \multicolumn{2}{|c|}{ Unadjusted** $^{* *}$} & \multicolumn{2}{|c|}{ Adjusted $^{* *}$} \\
\hline & $\%$ & $\mathrm{n}$ & $p$-value & $\begin{array}{c}\text { OR }(95 \% \\
\text { Cl) }\end{array}$ & $\mathrm{p}$-value & $\begin{array}{c}\text { OR }(95 \% \\
C l)\end{array}$ & $\mathrm{p}$-value \\
\hline \multicolumn{8}{|l|}{ Decay Status } \\
\hline Non active & 66.2 & 290 & 0.119 & 1 & & 1 & \\
\hline Active & 56.3 & 36 & & $\begin{array}{l}1.52 \\
(0.89- \\
2.59)\end{array}$ & 0.121 & $\begin{array}{l}1.54 \\
(0.90- \\
2.65)\end{array}$ & 0.115 \\
\hline \multicolumn{8}{|l|}{ PUFA } \\
\hline $\begin{array}{l}\text { Having no } \\
\text { conditions }\end{array}$ & 74.8 & 80 & 0.016 & 1 & & 1 & \\
\hline $\begin{array}{l}\text { Having at } \\
\text { least one of } \\
\text { the conditions }\end{array}$ & 62.3 & 246 & & $\begin{array}{l}1.79 \\
(1.11- \\
2.90)\end{array}$ & 0.017 & $\begin{array}{l}1.75 \\
(1.07- \\
2.84)\end{array}$ & 0.022 \\
\hline \multicolumn{8}{|l|}{ Plaque Index } \\
\hline $\begin{array}{l}\text { Normal or } \\
\text { small deposits } \\
(<1)\end{array}$ & 72.0 & 121 & 0.018 & 1 & & 1 & \\
\hline $\begin{array}{l}\text { Moderate or } \\
\text { severe } \\
\text { deposits }(>1)\end{array}$ & 61.4 & 205 & & $\begin{array}{l}1.62 \\
(1.08- \\
2.42)\end{array}$ & 0.019 & $\begin{array}{l}1.66 \\
(1.11- \\
2.51)\end{array}$ & 0.014 \\
\hline \multicolumn{8}{|l|}{ Gingivitis } \\
\hline $\begin{array}{l}\text { Normal or } \\
\text { mild }(<1)\end{array}$ & 75.2 & 106 & 0.003 & 1 & & 1 & \\
\hline $\begin{array}{l}\text { Moderate or } \\
\text { severe }(>1)\end{array}$ & 60.9 & 220 & & $\begin{array}{l}1.94 \\
(1.25- \\
3.00)\end{array}$ & 0.003 & $\begin{array}{l}1.98 \\
(1.27- \\
3.09)\end{array}$ & 0.003 \\
\hline
\end{tabular}

${ }^{*}$ Chi-squared test

*Logistic regression adjusted for age, gender, and education status of the parents

\section{DISCUSSION}

In this study, $64.9 \%$ of children reported having at least one performance affected by oral health problems. This prevalence was higher than the findings among children of a similar age group in Tanzania $(28.6 \%)^{17}$, and London $(40.4 \%)^{18}$, but lower than those in Brazil $(80.7 \%)^{19}$, and France $(73.2 \%)^{20}$.

In general, most of the studies have reported high prevalences of oral impacts. This may well be affected by the nature of the samples. However, those studies are all non-representative as this is not required for the validation process. Therefore, the comparison of prevalence across countries should be done ideally between representative samples because this would subsequently enable us to postulate whether there are cultural differences in the perceptions of oral impacts and also to assess the extent to which this may be affected by different socioeconomic or clinical profile between the samples. Hence, based on the abovementioned consideration, it was not possible to conduct this comparison in this study.

In this study, the most prevalent oral impacts were difficulty cleaning teeth $(40 \%)$ and eating (33.5\%). This result was not similar to that of most of related studies that had reported that eating was the most affected activity using the ChildOIDP in a general population ${ }^{17}$. However, this result was quite similar to the findings of another study using the Child-OIDP index in a Malaysian population ${ }^{9}$. When the most affected performance is cleaning teeth, it indicates a potential clinical oral health problem that is related to cleaning mouth such as gingivitis and high accumulation of plaque on the teeth. In our study, $32.52 \%$ of the participants had moderate until severe gingivitis, $37.12 \%$ reported having moderate to an abundant accumulation of plaque. Another study conducted in Sudan reported that $42.3 \%$ of children who had oral impact on cleaning, perceived impairments 
on gingival condition such as swelling, calculus, and gingival bleeding ${ }^{21}$.

The second affected performance in our study was eating, a finding that was not similar to the majority of studies that had eating as the most affected performances ${ }^{17-21}$. This was potentially contributed by the higher prevalence of decayed teeth among the participants (87.2\%). This result was similar to a study conducted in Sudan that reported $63.1 \%$ of children who had oral impact on eating perceived impairments such as toothache and decayed teeth ${ }^{21}$. A similar result was reported in a study that showing that dental caries experience has an indirectly effect through psychological factors to finally manifest as an oral impact on specific performances ${ }^{22}$.

This study has demonstrated that the Child-OIDP can be translated well linguistically and adapted culturally for preserving the face validity to be acceptable for children and the content validity at a conceptual level among a sample of 12 to 15year-old children in Jakarta. No such validated instruments that can be applied in a children setting are currently available in Indonesia, which is a gap for the development of this research field in this community, the Indonesian version of the Child-OIDP that demonstrated excellent internal consistency reliability, has thus indicated its potential applicability for child populations of similar ages in Indonesia.

The Cronbach alpha coefficient was 0.74 , which did not increase even when any item was deleted. This value has fulfilled the accepted threshold that requires a value of $0.70^{16}$. The value of alpha is obtained by the correlation between items and the number of items on a scale; therefore measures using fewer items, such as the ChildOIDP, are expected to have lower alpha values ${ }^{14}$, 15, 23. Furthermore, the alpha value decreased when any of the items were deleted, thus providing evidence that all the items are important to the establishment of the Child-OIDP. All item-total correlations were above the recommended value 0.20 and none of them were high enough to indicate redundancy in the scale or too low to suggest that they were part of different constructs ${ }^{16}$. In addition, the results revealed that the Indonesian Child-OIDP index items showed good positive correlations with one another and are relevant to constitute an index.

All these highly successful results clearly indicate the appropriate internal consistency of the Indonesian-version of the Child-OIDP. This reflects an adequate internal consistency reliability of the Indonesian version of the Child-OIDP which reflects there is no item irrelevance, item ambiguity, or sample variance in the Indonesianversion of the Child-OIDP index. Although these results are robust, they are preliminary because we did not assess test-retest (external) reliability throughout the entire process of validation. Establishing test-retest reliability or reproducibility using indices is a method to estimate the reliability of an instrument by administering the measure to the same targeted people on two or more different occasions in the same manner. This is followed by assessing the level of agreement using appropriate statistical methods; such as Kappa for categorical measures and intraclass correlation coefficient (ICC) for continuous variables.

In this analysis, the discriminant validity was not assessed using the Child-OIDP score, but using the prevalence of oral impacts. Therefore, the result led to initial validity results. This undoubtedly suggested that a comprehensive assessment of discriminant validity should be done using the Child-OIDP score in a future study where it is expected that we woud also assess the construct validity.

The bivariate analysis and logistic regression involving age, gender, and parents' education level, confirmed that the association between the presence of decayed teeth and the prevalence of oral impacts was not statistically significant $(p=0.121)$. This result was not similar to that of a majority of studies that had reported the significant association between OHRQoL and dental caries ${ }^{24,25}$. Nevertheless, this result was similar to that of several studies that had reported no association between OHRQoL and prevalence of dental caries $^{17,26}$.

It is expected that dental caries would lead to oral impacts when it is associated with oral symptoms, such as discomfort, pain, and functional limitation such as those among children who had several decayed teeth in their mouth. A study demonstrating association between OHRQoL and dental caries reported that children who had two or more decayed teeth suffered from significantly higher oral symptoms and functional limitation than those with less than two carious teeth ${ }^{25}$. However, caries can be an asymptomatic condition particularly during its early stages and also in chronic stages, which potentially did not affect daily activities ${ }^{27}$. In addition, a condition that affects children's performances due to oral health problems is related to psychological impacts, particularly aesthetic problems when the decayed teeth affect appearance and speech, in particular, the front teeth, including the first and second premolars ${ }^{28}$. An earlier study showed that those with higher dental caries experience scored higher for lower on self-confidence, lower on mental health, and somatisation, and had higher dissatisfaction with body image ${ }^{22}$.

As mentioned above, dental caries may potentially have an impact when it is related to dental pain. Thus, it is more likely associated with 
the severity of caries which is indicated by the PUFA index. Hence, in this study, children who had at least one problem as indicated by the PUFA index had an OR of having oral impacts of 1.79 (1.11-2.90) times than those who had no problems $(p<0.05)$. These findings were similar to another result showing that the presence of having a negative impact on OHRQoL was $33 \%$ greater among children with a PUFA score $>1^{25,29}$. Furthermore, those children who had poor oral hygiene indicated by a higher score of PI score $(\mathrm{OR}=1.62)$ and $\mathrm{Gl}$ score $(\mathrm{OR}=1.94)$, reported a significantly higher prevalence of oral impact. This result was similar to some studies using the Child-OIDP index that reported a higher prevalence of oral impacts among those children who had $\mathrm{PI}$ and $\mathrm{Gl}$ scores $>1^{30}$. This result confirmed that oral hygiene is an important concern in this population as shown by the fact that the oral impact on cleaning teeth was the most prevalent one.

\section{Limitations}

This study has some limitations. First, It was acknowledged in the beginning that this study merely assessed the prevalence of oral impact on daily performance thus we cannot construct the Child-OIDP score neither assess the frequency and severity of oral impacts. Regarding merely use of prevalence question, we were not able to do fully validation assessment and apply the outcome measure in practical settings such as needs assessment. Finally, as only Jakarta as a capital city of Indonesia, were selected for the sampling of the participants, our results are not representative of Indonesia. However, this study involved a large sample which potentially being adequate for visualizing bivariate and multivariate associations among those variables.

\section{CONCLUSIONS}

This study shows that the Indonesian Child-OIDP index is a measure of OHRQoL that can discriminate between groups with different clinical oral health status in terms of their prevalence of oral impacts. Further comprehensive research is required to fully assess the construct validity to ensure that the Indonesian version of the Child-OIDP is reliable and valid to be applicable in Indonesia.

\section{ACKNOWLEDGMENTS}

This research was supported by the Indonesian Ministry of Education and Indonesia Endowment Fund for Education.

\section{REFERENCES}

1. Cortes-Martinicorena FJ, Rosel-Gallardo E, Artazcoz-Oses J, Bravo M, Tsakos G. Adaptation and validation for Spain of the Child-Oral Impact on Daily
Performance (C-OIDP) for use with adolescents. Med Oral Patol Oral Cir Bucal. 2010;15(1):e106-11.

2. Gherunpong S, Sheiham A, Tsakos G. A sociodental approach to assessing children's oral health needs: integrating an oral health-related quality of life (OHRQoL) measure into oral health sevice planning. Bull World Health Organ. 2006;84 (1):36 - 42.

3. Abanto J, Carvalho TS, Bonecker M, et al. Parental reports of the oral healthrelated quality of life of children with cerebral palsy. BMC Oral Health. 2012;12:15.

4. Sheiham A, Tsakos G. A sociodental approach to assessing children's oral health needs: integrating an oral healthrelated quality of life (OHRQoL) measure into oral health service planning. World Health Organization. Bulletin of the World Health Organization. 2006;84(1):36-42.

5. Gherunpong S, Tsakos G, Sheiham A. A socio-dental approach to assessing children's orthodontic needs. The European Journal of Orthodontics. 2006;28(4):393-99.

6. Sischo L, Broder HL. Oral Health-related Quality of Life. Journal of Dental Research. 2011;90(11):1264-70.

7. Bowling A. Measuring disease : a review of disease specific quality of life measurement scales. 2nd ed. ed. Buckingham: Buckingham : Open University Press; 2001.

8. Sheiham A, Maizels JE, Cushing AM. The concept of need in dental care. Int Dent J. 1982;32(3):265-70.

9. Yusof ZYM, Jaafar N. A Malay version of the Child Oral Impacts on Daily Performances (Child-OIDP) index: assessing validity and reliability. Health and Quality of Life Outcomes. 2012;10.

10. Ahn YS, Kim HY, Hong SM, et al. Validation of a Korean version of the Child Oral Health Impact Profile (COHIP) among 8- to 15-year-old school children. Int J Paediatr Dent. 2012;22.

11. Atchison KA, Dolan TA. Development of the Geriatric Oral Health Assessment Index. Journal of Dental Education. 1990;54(11):680-87. 
12. Gherunpong S, Tsakos G, Sheiham A. Developing and evaluating an oral health-related quality of life index for children; the CHILD-OIDP. Community Dent Health. 2004;21(2):161-9.

13. Fayers PM. Quality of life : the assessment, analysis and interpretation of patient-reported outcomes. 2nd ed. ed. Chichester, England Hoboken, $\mathrm{NJ}$ : Chichester, England Hoboken, NJ : John Wiley \& Sons; 2007.

14. Streiner DL. Health measurement scales : a practical guide to their development and use. Fifth edition. ed: Oxford : Oxford University Press; 2015.

15. Shrout PE, Yager TJ. Reliability and validity of screening scales: effect of reducing scale length. J Clin Epidemiol. 1989;42(1):69-78.

16. Kline $\mathrm{P}$. The handbook of psychological testing. Second edition. ed: London : Routledge; 2000.

17. Mtaya M, Astrom AN, Tsakos G. Applicability of an abbreviated version of the Child-OIDP inventory among primary schoolchildren in Tanzania. Health Qual Life Outcomes. 2007;5:40.

18. Yusuf $H$, Gherunpong $S$, Sheiham $A$, Tsakos G. Validation of an English version of the Child-OIDP index, an oral health-related quality of life measure for children. Health and Quality of Life Outcomes. 2006;4:38-38.

19. Castro RAL, Cortes MIS, Leão AT, et al. Child-OIDP index in Brazil: Cross-cultural adaptation and validation. Health and Quality of Life Outcomes. 2008;6:68-68.

20. Tubert-Jeannin S, Pegon-Machat E, Gremeau-Richard C, Lecuyer MM, Tsakos $G$. Validation of a French version of the Child-OIDP index. Eur J Oral Sci. 2005;113(5):355-62.

21. Nurelhuda NM, Ahmed MF, Trovik TA, Åstrøm AN. Evaluation of oral healthrelated quality of life among Sudanese schoolchildren using Child-OIDP inventory. Health and Quality of Life Outcomes. 2010;8:152-52.

22. Foster Page LA, Thomson WM, Ukra A, Baker SR. Clinical status in adolescents: is its impact on oral health-related quality of life influenced by psychological characteristics? European Journal of Oral Sciences. 2013;121(3pt1):182-87.

23. Ware JE, Brook RH, Davies AR, Lohr KN. Choosing measures of health status for individuals in general populations. American Journal of Public Health. 1981;71(6):620-25.

24. Do LG, Spencer A. Oral health-related quality of life of children by dental caries and fluorosis experience. J Public Health Dent. 2007;67(3):132-9.

25. Alsumait A, ElSalhy $M$, Raine $K$, et al. Impact of dental health on children's oral health-related quality of life: a cross-sectional study. Health and Quality of Life Outcomes. 2015;13(1):110.

26. Robinson PG, Nalweyiso N, Busingye J, Whitworth J. Subjective impacts of dental caries and fluorosis in rural Ugandan children. Community Dent Health. 2005;22(4):231-6.

27. Zero DT, Zandona AF, Vail MM, Spolnik KJ. Dental caries and pulpal disease. Dent Clin North America. 2011;55(1):2946.

28. Topaloglu-Ak A, Eden E, Frencken JE. Managing dental caries in children in Turkey - a discussion paper. BMC Oral Health. 2009;9(1):1-8.

29. Praveen BH, Prathibha B, Reddy PP, et al. Co Relation between PUFA Index and Oral Health Related Quality of Life of a Rural Population in India: A CrossSectional Study. J Clin Diagn Res. 2015;9(1):Zc39-42.

30. Nurelhuda NM, Ahmed MF, Trovik TA, Åstrøm AN. Evaluation of oral healthrelated quality of life among Sudanese schoolchildren using Child-OIDP inventory. Health and Quality of Life Outcomes. 2010;8:152-52. 